\title{
Centrais de atendimento: a fábrica do sécu- lo XIX nos serviços do século $\mathrm{XXI}^{1}$
}

\section{Call centers: $19^{\text {th }}$ century factory in $\mathbf{2 1}^{\text {st }}$ century services}

\footnotetext{
${ }^{1}$ Artigo extraído da tese de Doutoramento de Selma Venco intitulada Tempos moderníssimos nas engrenagens do telemarketing, apresentada ao Departamento de Ciências Sociais Aplicadas da Faculdade de Educação da Universidade Estadual de Campinas (Unicamp), em 2006. Doutorado-sanduíche financiado pela CAPES.

${ }^{2}$ Doutora em Educação e Sociologia do Trabalho, pesquisadora colaboradora do Instituto de Filosofia e Ciências Humanas da Universidade Estadual de Campinas, Campinas, SP.
}

\begin{abstract}
Resumo
Este artigo aborda a racionalização no sistema capitalista e as relações sociais expressas em um tipo de trabalho que se expande no século XXI: o teleatendimento. A organização do trabalho estabelece ritmos de trabalho e pressão hierárquica para o aumento da produtividade, configurando condições de trabalho nocivas aos trabalhadores. Analisa-se, por um lado, o uso da tecnologia a serviço do aperfeiçoamento do controle do trabalho e o papel da gestão de pessoal no aumento da produtividade e, por outro, a resposta dos trabalhadores às imposições do capital.
\end{abstract}

Palavras-chaves: taylorismo, assédio moral, condições de trabalho, teleatendimento, formas de resistência.

\begin{abstract}
This article discusses rationalization in the capitalist system and the social relations expressed in a type of work practice that has expanded in the 21st century: the telemarketing. In order to raise productivity, labor management demands working rhythms and hierarchical pressures that cause deleterious conditions to workers. The article analyses not only the use of technology for improving work control and the role of staff management in increasing productivity, but also workers' response towards the capital requirements.
\end{abstract}

Keywords: taylorism, moral harassment, working conditions, telemarketing, ways of resisting. 


\section{Introdução}

O presente artigo visa discutir as condições de trabalho em um setor de expansão recente no Brasil e no mundo: as centrais de atendimento, também conhecidas como call centers ou empresas de telemarketing.

A atividade que nelas se desenvolve parte da combinação de elementos modernos, como a fusão da informática e das telecomunicações - a telemática -, mas faz uso de formas tradicionais de prescrição e controle do trabalho, inspiradas na “organização científica do trabalho” elaborada por Frederich Taylor (1995). Falamos de uma atividade realizada integralmente via telefone, com abrangência nacional e internacional e que desponta no cenário econômico como um dos grandes empregadores da força de trabalho dos anos 2000. Em 2005 eram, no Brasil, 600 mil trabalhadores distribuídos em 1.827 empresas, das quais 250 são terceirizadas. São números ainda modestos quando comparados aos de outros países como os Estados Unidos, que contam com 50 mil call centers (BATT, DOELLGAST \& KWON, 2004), a Alemanha (GRIP, SIEBEN \& JAARSVELD, 2005), com 1.992, ou a França (LECHAT \& DELAUNAY, 2003), com 3.300, apesar do Brasil apresentar maior concentração de trabalhadores por empresa do que estes.

Essa categoria profissional é predominantemente jovem, feminina e com escola- ridade média equivalente ao ensino médio completo, com presença expressiva de estudantes universitários de instituições de ensino privadas.

A presente análise é sustentada por pesquisa qualitativa finalizada em 2006 junto a duas empresas terceirizadoras de serviços localizadas em São Paulo, Brasil, estando excluídas as vinculadas às operadoras de telefonia. Tal opção deveu-se à peculiar possibilidade dessas empresas estarem presentes em diversas cadeias produtivas, não apenas no setor da telefonia. Escolheram-se os dois call centers com o maior número de postos de trabalho, porque se pressupôs que tendiam - face ao quadro observado em estudo anterior - a praticar uma organização do trabalho mais próxima à industrial. São unidades que, inclusive, ocupam antigos galpões fabris em zonas industriais.

Fizeram-se 33 entrevistas em profundidade, a partir de um roteiro semi-estruturado, visando captar a percepção da atividade pela ótica dos operadores de telemarketing, dos gerentes operacionais e de recursos humanos e dos dirigentes sindicais, representantes tanto de trabalhadores como do patronato. Cabe ressaltar que os depoimentos dos teleoperadores foram coletados fora dos seus locais de trabalho.

\section{A organização do trabalho de teleatendimento}

A despeito do uso de tecnologia de ponta no setor, apreende-se um ambiente marcado pela prescrição e pela racionalização do trabalho (BUSCATTO, 2002; COSSALTER, 2002; LECHAT \& DELAUNAY, 2003; VENCO, 2003).

Diversas pesquisas têm apontado as características tayloristas na organização do trabalho de teleatendimento (BUSCATTO, 2002; VENCO, 2003; LECHAT \& DELAUNAY, 2003), tais como o parcelamento de tarefas, a divisão entre o planejamento e a execução, a prescrição do trabalho e o controle dos tempos e movimentos - movimentos agora expressos pela $\mathrm{VOz}$ dos atendentes, que passa a ser o elemento principal da atividade, substituindo os músculos da produção industrial do passado.
A socióloga do trabalho francesa Marie Buscatto (2002, 2002a) cogita que as centrais de atendimento sejam as fábricas modernas ao considerar que a organização do trabalho praticada nessas empresas é marcada pelo trabalho repetitivo, baseado na reprodução de falas padronizadas expressas nos scripts, no tempo de atendimento controlado e no controle individual dos trabalhos, os quais reproduzem os procedimentos industriais nas relações comerciais. Para essa autora, por trás desse pretenso Eldorado tecnológico (2002, p.100), há uma realidade difícil, marcada pela flexibilidade nas relações trabalhistas e por más condições de trabalho:

\footnotetext{
Taylorização, estresse e trabalho penoso, precarização, baixa remuneração e flexibilidade da mão-de-obra são palavras-chave atreladas a essas organizações. As centrais
} 
de atendimento seriam fábricas modernas e os trabalhadores, os novos operários do setor terciário. (BUSCATTO, 2002, p.100)

Também investigando a organização do trabalho nos call centers, Olivier Cousin (2002) constata que essa atividade "simboliza a taylorização do terciário, onde a informática permite elevar a uniformização das tarefas” (2002, p. 502) em função principalmente da aplicação das normas e dos procedimentos determinada pela gerência, por ele denominada "hiper-racionalização do trabalho" (2002, p. 510). No entanto, pondera que, mesmo nessa situação, os operadores têm margem de autonomia para o desenvolvimento de sua atividade. Tal como no período industrial, quando se sabotava o trabalho ou o tornava mais lento, esses trabalhadores também desenvolveram formas de resistência que adulteram as demandas gerenciais.

O forte predomínio do taylorismo indica que a organização do trabalho implantada nesse setor da economia encontra respaldo na sofisticação da tecnologia, posto que toda a movimentação nas posições de atendimento (PA) é registrada pelo software: o número de ligações feitas e recebidas, o tempo de atendimento, as pausas, as vendas realizadas, as estatísticas dos resultados das ligações, a indicação de clientes à espera e o tempo excedido de atendimento, entre outros dados. A tecnologia atua ainda por meio de um equipamento multifuncional que é fundamental para a racionalização do trabalho e o aumento da produtividade: a URA, Unidade de Resposta Audível, que, automaticamente, distribui as ligações recebidas entre os operadores há mais tempo ociosos e, grava, na íntegra, todos os atendimentos.

Ao controle efetivamente expresso na gravação das ligações, soma-se a possibilidade da supervisão simultânea - o supervisor pode ouvir o atendimento e interferir no contato, sugerindo argumentos e propostas de venda no momento exato em que está sendo executada. Esse artifício é amplamente empregado no controle dos trabalhadores, cujas falas são expostas em programas de treinamento para o aprimoramento das performances e patenteia a autoridade da empresa sobre as atitudes junto aos clientes.

O software, desenvolvido para as centrais de atendimento, intensifica a monitoração dos trabalhadores e visa limitar sua autonomia. Contém scripts orientadores das falas dos operadores - de modo que todo contato com os clientes seja norteado por sua leitura - que ficam expostos nas telas e indicam como recepcionar o cliente e informá-lo sobre o produto a ser vendido ou os serviços a serem prestados. A idéia é imprimir maior objetividade às falas, reduzindo-se o tempo de atendimento. Além disso, assegura a "fidelidade" dos operadores aos valores empresariais. Conforme Heloani:

O objetivo desses enunciados consiste na imposição de um quadro de referências que obrigatoriamente seja utilizado pelos indivíduos no interior da empresa e, ao fazê-lo, os trabalhadores reforçam o corpo de representações inerentes ao conjunto de valores e à codificação que impõem à realidade. Em síntese, o sistema de regras se estrutura como uma gramática dirigida à identificação com os valores da empresa, em particular à subordinação necessária do trabalho ao capital e, nesse processo, a linguagem desempenha papel essencial. (HELOANI, 1996, p. 97)

A história do trabalho revela práticas pautadas por normas e prescrições que, de um lado, resultam em relações sociais específicas e, de outro, consolidam o ambiente de trabalho quanto às instalações físicas sob uma arquitetura tributária das condições de trabalho aqui compreendidas como construção social. Para além da iluminação, da ventilação, dos ruídos e da adequação do equipamento ao trabalhador, há práticas que incidem também sobre a cadência do trabalho e a subordinação aos prazos, bem como sobre as disposições das chefias imediatas e da gestão mais ampla de pessoal.

Ainda que as situações de trabalho sejam concretas e idênticas, são vividas pelos indivíduos de acordo com suas trajetórias pessoais. Nessa perspectiva, a psicanalista Marie Grenier-Pezé observa que é irreal supor que os trabalhadores consigam desvencilhar-se de sua história de vida, deixando-a "atada a um cinto no vestiário da empresa”, para exercer sua atividade (2001, p. 30). Consoante Michel Gollac e Serge Volkoff (2000), as condições de trabalho conformam uma questão política e social e são freqüentemente palco de conflitos sociais, uma vez que são vistas por prismas díspares entre trabalhadores e empresários.

A racionalização do trabalho é estreitamente ligada às condições em que se dá, à medida que atua permanentemente na dominação do capital sobre o trabalho, 
${ }^{3} \mathrm{O}$ atendimento receptivo recebe ligações dos clientes e dá orientações, informações, suporte técnico ou prestação de serviços, como nos SAC ou nas informações sobre serviços públicos, financeiros etc. Nesta modalidade, destacase a equipe de retenção, que também recebe chamadas, mas à qual cumpre reverter pedidos de cancelamento de determinado serviço ou produto - TV a cabo, assinatura de revista, jornal, banda larga etc. $\mathrm{O}$ atendimento ativo parte das centrais e é praticamente sinônimo de venda, embora inclua a informação de autorizações para exames médicos - no caso dos planos de saúde - ou as boas-vindas a um novo cliente. Para esse tipo de abordagem, o código de ética em telemarketing prevê horários de segunda a sexta-feira, das 9 h00 às 21 h00 e, aos sábados, das 10 h00 às $16 \mathrm{~h} 00$, conforme o artigo $9^{\circ}$ do Código dos Contatos Ativos. $\mathrm{O}$ atendimento híbrido reúne o receptivo e o ativo, exigindo mais destreza e experiência do operador, que deve fazer seu trabalho em ambas situações.

respaldando-se em novas tecnologias voltadas para o aperfeiçoamento do controle dos movimentos e da produtividade dos trabalhadores. Essa concepção capitalista acentua a fragmentação e as desigualdades que delineiam as relações de trabalho e faz com que se desenvolva o espaço produtivo em bases tayloristas.

Esses fatores expressam-se em relações de trabalho num contexto socioeconômico neoliberal, resultando em desemprego e precarização do trabalho. Lembrando-se de que o temor ao desemprego - que se torna parte das relações de trabalho, na medida em que é usado para ressaltar a importância de se ter um trabalho - leva os trabalhadores a adequarem-se às normas disciplinares e de produtividade. Como elucidam

\section{Intensificação e precarização do trabalho}

A partir das referências do sociólogo do trabalho Jean-Pierre Durand (2004), podese analisar a intensificação do trabalho por dois ângulos: o da eliminação dos tempos mortos entre as tarefas, suprimindo-se o período de recuperação dos trabalhadores ou sobrepondo-se tarefas, e o aumento de sua velocidade de execução.

Ambas dimensões são observáveis nas três modalidades de atendimento das operações de teleatendimento: ativo, receptivo e híbrido ${ }^{3}$. A tecnologia empregada atua no aumento da cadência do trabalho. No atendimento ativo, há um discador automático programado para que as ligações cheguem às PA ininterruptamente - encerrado um contato, automaticamente se disponibiliza uma nova chamada para o operador.

Na França, a temporização - intervalo entre duas chamadas -, oscila entre 7 e 20 segundos, conforme a missão principal da central, resultando em descansos de 5 a 12 minutos por hora, determinados pelo próprio operador, em consonância com seu chefe de equipe e conforme o número de clientes em espera. De acordo com os depoimentos coletados por Delaunay, nota-se uma certa autonomia negociada para as pausas, que podem chegar a até 24 minutos (LECHAT E DELAUNAY, 2003), especialmente nas operações receptivas, sendo esse um dos pontos das pautas de negociação entre empregadores e sindicatos.

No teleatendimento, a simultaneidade de tarefas é parte da organização do trabalho e visa agilizar a produção. Nas entre-
Zune e Pichault (2000, apud DESSUS, 2002, p. 40), ocorre hoje um "novo contrato psicológico”, que imputa exclusivamente aos próprios indivíduos a responsabilidade de conseguirem um emprego e, para além de sua qualificação técnica, características como sua capacidade de integração, amabilidade e engajamento na empresa.

Esses fatores estão associados a uma organização do trabalho fundamentada na prescrição e no controle, mas Gollac e Volkoff (2000) ressaltam que, mesmo nas atividades repetitivas, não é possível desprezar as variações e os imprevistos somados ao suposto envolvimento do trabalhador com sua tarefa como forma de valorizar suas próprias habilidades para o trabalho.

vistas realizadas, foi recorrente a afirmação da necessidade de executarem muitas tarefas ao mesmo tempo - preencher os dados cadastrais pedidos no software, ouvir o cliente, o supervisor ou o cliente externo -, indicando a sobreposição de diferentes etapas do trabalho, o que exige desses trabalhadores a mobilização de suas capacidades auditiva e de concentração.

O sistema do supervisor indica a situação de cada integrante de sua equipe, dando informações sobre pausas e ligações em curso. Esse acompanhamento é facilitado pela introjeção individual do controle, decorrente das diversas formas de pressão exercidas sobre os operadores: a contínua emissão de relatórios de produtividade, as metas diárias e mensais como determinantes do salário ou da promoção na carreira e, sobretudo, o medo de perder um vínculo formal de trabalho, freqüentemente mencionado pela supervisão, tendo em vista os altos índices de desemprego, em particular entre jovens, faixa etária predominante no setor.

A precarização das relações de trabalho propicia a intensificação do trabalho e a individualização dos comportamentos, neutralizando a mobilização coletiva e generalizando "o silêncio" e o "cada um por si”. O medo da perda do emprego induz a condutas de dominação ou de submissão (GRENIER-PEZÉ, 2001). Instaura-se no ambiente de trabalho um clima de permanente competição, tanto individual quanto coletivamente, suportável apenas pela 
perspectiva da manutenção do emprego (ALONZO, 1998).

As equipes são estimuladas a concorrer entre si por melhores vendas, para ser o melhor vendedor, pela decoração mais criativa do espaço físico ou pela fantasia mais original $^{4}$, por exemplo. São recursos utilizados pelas empresas objetivando manter um clima competitivo e estimulante, para se ultrapassarem diariamente os patamares de vendas. A palavra "motivação" apareceu muitas vezes nos depoimentos, especialmente nos das chefias, reiterando a constatação de Noël Lechat de que o cumprimento do trabalho diário em si não basta - as empresas querem um "engajamento da alma” (LECHAT \& DELAUNAY, 2003, p. 36).

Durand e Girard (2002) sublinham a importância de se distinguirem alguns conceitos que permeiam as situações de trabalho, entre eles a massa de trabalho - quantidade de trabalho por unidade de tempo. Entre os call centers pesquisados, estabeleceu-se um número mínimo de ligações diárias em torno de 140. Esse conceito difere do de carga de trabalho, que pode lhe ser complementar, conforme a área de especialização. A Psicologia do Trabalho a concebe como o dispêndio de energia humana na atividade produtiva. Para o ergonomista Maurice Montmollin (1984), a abordagem psicológica é clássica e há que lhe incluir o gasto energético para se tolerar o acúmulo de tarefas, ressaltada ainda a importância da incorporação do saber-fazer individual no processo de trabalho. Em outras palavras, a tarefa prescrita será sempre realizada de diferentes formas, conforme a mobilização das qualificações que cada trabalhador emprega no seu trabalho.

Sobre o trabalho prescrito, afirmam Dejours e Molinier (1994) que há uma grande distância entre a determinação do trabalho e a iniciativa do trabalhador, ponderando que, para além desse debate, o interesse acadêmico deveria recair sobre a forma como os trabalhadores enfrentam a questão. Para eles, há aspectos que não podem ser antecipados pela prescrição, pois se relacionam diretamente aos indivíduos - por exemplo, a engenhosidade, a coordenação e a cooperação. Atrelados à organização do trabalho, esses três elementos atestam que o trabalho necessariamente evoca a inteligência, que se manifesta especialmente em situações não previstas na prescrição, por mais repetitiva e pré-determinada que seja a tarefa. Segundo os mesmos autores, esse ajuste entre o prescrito e o realizado constitui a parte enigmática do trabalho, pois envolve a criatividade e a subversão dos procedimentos. Além disso, arrolam também, como elemento de ruptura com a prescrição, o estabelecimento de relações cooperativas entre trabalhadores. Para eles, a organização do trabalho privilegia invariavelmente a disciplina e não a colaboração, apesar dos trabalhadores serem designados por diversas corporações, inclusive nas empresas pesquisadas, como colaboradores. Como ressaltam os autores, “a cooperação não é um produto mecânico da organização: ela não se decreta e nem se prescreve" (DEJOURS \& MOLINIER, 1994, p. 38), e essa dimensão do trabalho só é possível pelo estabelecimento de relações de confiança entre os trabalhadores.

Embora concordemos com Dejours e Molinier (1994), a presente pesquisa constatou o intuito da gestão de pessoal de reavivar o "espírito de equipe", a cooperação e a solidariedade em momentos de trabalho mais intenso, seja pelo grande número de clientes à espera, seja por haver equipes com dificuldade de atingir a meta estipulada. A solidariedade entre os trabalhadores é, portanto, "valorizada" em favor do aumento da produtividade, mas há os que a entendam de outro modo. Entre os que têm menos tempo na profissão, ser solidário é ajudar o colega, a equipe e depois comemorar coletivamente o êxito. Para os demais, é mero exercício de cooptação para a obtenção de maiores lucros e do desempenho máximo de cada um deles.

Para os trabalhadores, a engenhosidade é a forma de suportarem a carga de trabalho e, ao mesmo tempo, de alcançarem as metas estabelecidas e, portanto, sofrerem menos pressão.

A engenhosidade é empregada frente a situações imprevistas, sem respostas preestabelecidas pela chefia imediata. A despeito do tratamento infantilizante que recebem da supervisão e da falta de respostas aos problemas que enfrentam, os operadores criam uma argumentação própria, com dupla função: satisfazer ao cliente e transmitir segurança no negócio que firmaram com a empresa.

Assim, a despeito da prescrição, esse trabalho demanda a mobilização das qualificações individuais de modo a se enfrentar a multiplicidade de tarefas simultâneas e os contratempos não solucionados a contento.
${ }^{4}$ Os operadores são convocados a trabalhar com fantasias temáticas, como anos 60, super-heróis, olimpíadas etc. 
${ }^{5}$ Sobre o cenário internacional, ver Venco, S. Tempos moderníssimos nas engrenagens do telemarketing. Tese de doutoramento apresentada no departamento de Ciências Sociais Aplicadas da Faculdade de Educação, UNICAMP, 2006. A exemplo das pesquisas realizadas pela Universidade de Cornell, nos EUA, por BATT, R., DOELLGAST, V. e KWON, H. The U.S. Call center industry, 2004: national benchmarking report. Estados Unidos: Cornell University, 2004; pelo Laboratório de Economia e Sociologia do Trabalho (LEST/CNRS), realizada por LANCIANO-MORANDAT, C., NOHARA, H., TCHOBANIAN, R. French Call Center Industry Report, 2004, na França; pela Faculdade de Economia e Administração da Universidade de Maastricht por GRIP, A., SIEBEN, I. e JAARSVELD, D. van. Employment and industrial relations in the Dutch call center sector. Maastrich: Research Centre for Education and Labour Market, 2005, na Alemanha; e pelo Instituto de Psicologia do Trabalho da Universidade de Sheffield, no Reino Unido, por HOLMAN, D., WOOD, S., STRIDE, C. Human Resource Management in Call Centres, 2004.

${ }^{6}$ Jornal Folha de S. Paulo, 14 março de 2004.

${ }^{7}$ Artigo 482 da Consolidação das Leis do Trabalho (CLT).
Nesse sentido, os operadores dependem de sua capacidade de argumentar frente às negativas dos clientes contatados, de se adaptar a cada interlocutor sua linguagem, suas idiossincrasias, suas objeções à compra do produto - e de ouvir pacientemente as demandas e reclamações dos clientes, mesmo quando pressionados pelo tempo médio de atendimento (BUSCATTO, 2002; COSSALTER, 2002).

Essa autonomia não é concedida totalmente pela organização do trabalho e essa

\section{O trabalho sob pressão}

A estandardização do trabalho nos call centers é complementada por um conjunto de regras que visam determinar certos comportamentos e a disciplina para o trabalho. As interdições referem-se a comer, fumar, conversar, fazer ou receber ligações no trabalho e sair do seu posto de atendimento; em algumas empresas, chega-se a exigir pedido formal para se ir ao toalete.

A disciplina faz parte da organização do trabalho e é observada em países desenvolvidos como, por exemplo, a França, cujas centrais se pautam por formas de controle dos trabalhadores muito semelhantes às do Brasil. Dessus (2002) observa particular semelhança entre as disciplinas aplicadas no sistema escolar e nos call centers - ambas com base em "regras, advertências, sanções e recompensas", além de atitudes infantilizadas e infantilizadoras da supervisão. Nos depoimentos que colhemos, o ambiente de trabalho foi constantemente comparado com o da escola, cuja lembrança é quase sempre negativa ao se reviverem o exercício da autoridade e a divisão hierárquica de saber e poder - que estão longe de se configurarem como ambientes apoiados em relações mais democráticas, participativas e de respeito, seja entre alunos, seja entre trabalhadores.

Os supervisores atuam diretamente na construção do poder disciplinar, sendo usualmente comparados, na literatura e na mídia francesas, aos antigos contramestres das fábricas (DESSUS, 2002; LECHAT \& DELAUNAY, 2003), cuja palavra de ordem é invariavelmente: "bater a meta". As coações descritas pelos trabalhadores são diversas. Um jornal paulistano de grande circulação, por exemplo, descreve uma situação em que um supervisor usava um martelo de plástico para bater na cabeça é uma das razões que levam aos pedidos de demissão, como se constatou em pesquisas internacionais ${ }^{5}$. Gilbert de Terssac (1992) concorre para a compreensão da autonomia no trabalho caracterizando-a como uma concessão determinada aos trabalhadores para executarem seu trabalho. Pondera, contudo, que a autonomia não se instaura pela simples substituição das regras formais estabelecidas por outro conjunto de normas, mas por soluções que permitem melhores resultados.

dos operadores, pedindo mais vendas. A operadora que descreveu essa situação perdeu 14 quilos em seis meses e passou a sofrer de uma depressão que, segundo ela, agravou-se após seguidos atos dessa natureza $^{6}$.

Na visão dos operadores, as chefias são sempre autoritárias e unilaterais, sem concessões expressivas para o diálogo sobre o trabalho e seu ritmo. As pressões sofridas embotam nos operadores a percepção de que também o supervisor sofre reprimendas semelhantes de seus superiores e que deve, por força do cargo, fortalecer na equipe o ânimo e a disposição para o trabalho.

As entrevistas realizadas foram reveladoras das condições de trabalho nas centrais de atendimento, pois, a despeito dos esforços para se abordarem outros aspectos do trabalho, todos os operadores ouvidos, especialmente os do atendimento ativo, voltavam às pressões por produção, repetindo continuadamente a expressão dos supervisores: "Vamos bater a meta".

Os trabalhadores suportam o comportamento da supervisão em grande medida por medo do desemprego, por dependerem daquele trabalho para estudar ou arcar com despesas familiares ou, ainda, pelo fato de ser, para $45 \%$ dos operadores, o primeiro emprego, ou seja, por serem pessoas menos experientes quanto aos limites do exercício do poder.

Pelo lado da gestão, recoloca-se permanentemente a possibilidade da perda do emprego, com constantes ameaças de justa causa com base na percepção da desinformação acerca dos direitos trabalhistas. As ameaças de demissão por justa causa ${ }^{7}$, recorrentes nos depoimentos, não só são uma forma de pressão pela manutenção da 
disciplina, mas, também, um expediente para induzir pedidos formais de demissão voluntária.

Um dos relatos coletados é exemplar: com dois anos e meio de empresa, uma operadora integrava a "melhor equipe de vendas" da casa. O trabalho repetitivo, a pressão por aumento da produtividade e os maus tratos da supervisão foram arrefecendo seu estímulo para o trabalho. Desde então, foi sendo trocada de equipe e hoje compõe a "pior equipe", segundo a supervisão. Seu desânimo e sua inadequação a esse tipo de organização da produção fizeram com que ela pedisse diversas vezes a inclusão de seu nome na lista de desligamentos da empresa. Com o tempo, a entrevistada passou a sofrer crises compulsivas de choro a cada constatação de que seu nome não constava da lista. Em dado momento, quando ela voltava das férias, a chefia alegou estar em posse de uma gravação cujo julgamento, feito pela empresa e pela empresa-cliente, indicava um comportamento insinuativo com determinado cliente. A solução proposta pela empresa era que ela pedisse demissão ou, em caso contrário, seria demitida por justa causa.

Entre os itens abordados na Consolidação das Leis de Trabalho, há um que parece ser usado para sustentar situações como essa: o que se refere à "incontinência de conduta ou mau procedimento", marcado por excessos baseados em hábitos e costumes, falta de moderação na linguagem, ofensa ao pudor etc. Ou seja, trata-se de um julgamento apoiado na moral e com forte caráter subjetivo.

Essa situação deriva da conjugação entre a possibilidade, facultada pela tecnologia, de se gravarem todos os atendimentos - e disso ser usado como forma de pressão para exigirem-se certos comportamentos e o medo dos trabalhadores de terem sua carreira profissional marcada por uma demissão por justa causa, tida no senso comum como falha gravíssima, e sofrer a conseqüente redução dos direitos financeiros na rescisão contratual.

A situação enfrentada por essa operadora deve ser vista para além da perspecti- va do julgamento moral da chefia, mas enfocando-se também as relações sociais de sexo - trata-se de uma coação sexista para omitir-se o motivo real do desligamento: a queda da produtividade. Como elucida Hirigoyen:

Quando um assalariado se desmotiva, ninguém lhe pergunta sobre as razões de seu desânimo, mas é rejeitado por não conformidade, por não ser suficientemente combativo (HIRIGOYEN, 2002, p.189).

$\mathrm{O}$ gerente me disse que o banco $\mathrm{X}$ pegou uma gravação minha [em] que eu dava confiança para o cliente, e que não quer mais você na operação dele... eu respondi: "Não vem com conversa para cima de mim, porque nem que eu quisesse eu faria isso, porque sei que as conversas são gravadas e eu não sou louca. E eu sei que eu não fiz isso e eu quero essa gravação". (Operadora de telemarketing, 22 out. 2004)

A título de ilustração, vale mencionar que o desfecho dessa situação não foi o previsto pela empresa. A operadora que requereu a gravação procurou imediatamente orientação jurídica junto ao sindicato e permanece até hoje na empresa, embora tenha sido transferida para outra operação. A gravação jamais lhe foi mostrada e outros supervisores e gerentes declararam desconhecer sua existência.

A pressão é o leitmotiv no trabalho em telemarketing e se desencadeia em efeito cascata por todos os grupos hierárquicos: o cliente externo pressiona a empresa terceirizada pela ampliação das vendas, a gerência geral do call center faz o mesmo com o coordenador, que recai sobre o supervisor e a monitoração e, estes, sobre os operadores. É uma pirâmide de coações com efeito cumulativo que determina o ritmo de trabalho, ações agressivas de vendas e atendimento racionalizado. Assim, ser capaz de trabalhar sob pressão é condição sine qua non para ingressar e permanecer no telemarketing. Na opinião de um dos empresários entrevistados, saber trabalhar sob pressão é fundamental para a qualificação profissional de qualquer indivíduo, quaisquer que sejam suas perspectivas ou habilidades e, portanto, imprescindível para a obtenção de um novo posto de trabalho no mercado.

\section{A construção nem sempre silenciosa das condições de trabalho}

As entrevistas realizadas ressaltam os constrangimentos diários a que são submetidos os operadores e suscitam indagações teóricas acerca dos limites que separam a pressão no trabalho e o assédio moral. Entende-se que as diversas formas de in- 
tensificação do trabalho geram pressão no trabalho, tanto pela cadência e velocidade com que os trabalhadores são obrigados a imprimir a suas ações, quanto por determinadas práticas gerenciais voltadas prioritariamente para o estímulo à produção, e é nesse aspecto que está a linha tênue entre as duas situações.

Marie-France Hirigoyen (2002) define como assédio moral atitudes que superam as discriminatórias - quanto à raça, gênero, orientação sexual ou qualquer outra -, infundindo humilhação ou constrangimento. Com base nesse conceito, consideram-se aqui os atos que envolvem algum grau de ofensa pessoal. A partir do conceito formulado por Michèle Drida, Marie GrenierPezé aponta o assédio moral como algo sistematicamente instaurado no ambiente de trabalho, "manifestando uma intenção consciente ou inconsciente de anular e destruir" (DRIDA, 1999, apud GRENIERPEZÉ, 2001, p. 30). Na concepção de Grenier-Pezé, trata-se de uma:

técnica de destruição visando de maneira deliberada à descompensação do sujeito a fim de obter sua rendição emocional aos fins econômicos ou de usufruto pessoal (idem, p.39).

Entre os nossos entrevistados, foi sintomática a constatação de um movimento cíclico dos operadores. Mesmo que se procurasse investigar aspectos diversos relativos ao trabalho, todos, sem exceção, respondiam e voltavam rapidamente ao relato de situações em que se sentiram ofendidos pela chefia imediata.

Entre os gerentes entrevistados, por sua vez, a percepção da pressão por aumento da produtividade também é constante e, segundo eles, o operador deve se adequar a esse ritmo, dadas as características do setor, mas negam que haja tratamentos desrespeitosos entre as diferentes posições hierárquicas dentro da empresa.

As sujeições à pressão no interior das empresas de teleatendimento são freqüentes e ocorrem tanto no plano individual quanto no coletivo. A pressão para o cumprimento das metas e para a observância do tempo de atendimento e a atuação direta da supervisão no controle da produção configuram a gradual "insuportabilidade" das condições de trabalho para muitos operadores.

O contínuo fluxo de trabalho leva alguns supervisores a estabelecerem normas para o uso dos toaletes, situação relatada pelos entrevistados com indignação e vergonha. Essa circunstância é agravada pela tensão que marca o comportamento dos supervisores - que, por sua vez, também são pressionados para o cumprimento das metas - e pelas ofensas que fazem ao executar o trabalho. Entre os entrevistados que tiveram, ao longo de sua carreira, a oportunidade de serem chefiados por uma pessoa mais ponderada, as opiniões são unânimes - a empresa não costuma manter no cargo uma pessoa com tal perfil.

Os insultos são provocados invariavelmente por questões quantitativas, não relacionadas à qualidade do atendimento, e atuam diretamente sobre a moral dos trabalhadores.

Também na França observa-se tal relação entre níveis hierárquicos. Pesquisa sobre as centrais de atendimento na França constatou que $62,5 \%$ dos trabalhadores dos call centers terceirizados sentem-se assediados moralmente. E o tratamento infantilizador das chefias foi apontado por $75 \%$ dos operadores nas empresas terceirizadas e por $83 \%$ nas centrais de atendimentos internas (LECHAT \& DELAUNAY, 2003).

A gerência faz mapas de controle das metas, com estatísticas diárias e hora a hora e, dispondo de um conjunto de informações que aponta os melhores horários para vendas e a média de vendas ou de atendimentos por período, atua de modo a recuperar, atingir ou ultrapassá-las. Numa das empresas pesquisadas, ações como essas se materializam numa "reunião dos zerados”, conforme denominação dos operadores. Em algum momento, deslocam-se da operação todos aqueles que até então não fizeram nenhuma venda. Nessa reunião, presidida pelo supervisor, muitas vezes acompanhado do coordenador da operação, fazem-se ofensas mais graves do que as que usualmente ocorrem no local de trabalho.

Depreendemos que as mulheres são mais suscetíveis a essas situações de constrangimento. Os homens entrevistados demonstraram enfrentar mais as ofensas e ameaças das chefias do que as mulheres, possivelmente respaldados na imagem da personalidade masculina socialmente construída, concretizando a concepção de Helena Hirata (1998) acerca da "sexuação do social”, ou seja, a de que a divisão sexual do trabalho é inseparável das relações sociais de sexo, marcada pela opressão que também é socialmente construída. A pes- 
quisa mostra que, por razões como essa, as mulheres deixam seus postos de trabalho mais facilmente que os homens e, reiterando o exposto acerca da organização do trabalho, que a predominância de mulheres na produção não é casual, mas uma opção de gestão da força de trabalho.

Tal conclusão é confirmada no estudo de Hirigoyen (2002), em que o assédio moral tem uma nítida diferença entre os sexos: 70\% são mulheres, revelando a importância de analisar esses dados à luz da conjuntura sociocultural, como, por exemplo, os esforços de alguns países como a Alemanha e o Canadá no sentido da promoção da igualdade entre os sexos.

Expressões como "corredor do choro" ou "o banheiro é lugar de choro no telemarketing" são reveladoras de uma situação penosa nos locais de trabalho. Conforme Hirigoyen (2002), as mulheres são mais suscetíveis às relações de dominação em razão da construção social do seu comportamento, devendo assumir posturas mais afáveis, pacientes e submissas.

Tanto quanto um ambiente ocupacional de difícil aceitação, as entrevistas revelaram inúmeras e recorrentes questões sobre a saúde física e a mental dos operadores.

Conforme um dirigente sindical da categoria: "o telemarketing está criando um exército de jovens doentes" ou, nas palavras de Galasso (2005, p. 194), uma "juventude dolorida à beira de um ataque de nervos". A incidência de síndrome do pânico ${ }^{8}$ e depressão entre esses trabalhadores é

\section{As defesas construídas}

Procurou-se mostrar como a organização e as condições do trabalho nas centrais de atendimento conformam um universo de pressão, intensificação do trabalho e controle sobre os operadores. No entanto, a despeito da rigidez das regras e das normas, os trabalhadores criam formas de resistência, estabelecendo códigos de confiança entre si, constituindo, nas palavras de Danièle Linhart (2004), uma alquimia incontrolável pela direção, estrategicamente consolidada para fazer frente a condições de trabalho e de poder caracterizadamente insuportáveis, ainda que autores como Terssac (1992), por sua vez, definam a situação de trabalho como uma construção social, negando, portanto, o determi- alta. Entre os entrevistados, todos mencionam esses males, se não em si mesmos, em algum colega próximo, tomando contato precoce com as doenças psíquicas.

Segundo Lechat e Delaunay (2003, p. 36): "humilhados e desvalorizados, os operadores não encontram saída que não a demissão”. Resultam daí os altos índices de rotatividade e absenteísmo por nós encontrados: em uma das empresas pesquisadas, a rotatividade é de $85 \%$ ao ano.

No decorrer das entrevistas, a lesão por esforços repetitivos (LER) foi sistematicamente lembrada, mas, a despeito de todos terem se declarado portadores da doença, esta foi obnubilada por males relativos ao estresse decorrente da pressão no trabalho.

$\mathrm{Na}$ França, os altos índices de rotatividade das centrais de atendimento são atribuídos às condições a que se submetem os operadores, fator responsável pela demissão (DESSUS, 2002).

Assim, vê-se que os limites entre a pressão por produtividade e o assédio moral são sutis, ambos sugerindo, porém, como afirma Heloani (2003, p. 5):

(...) uma intencionalidade, (...) seguida de sua conseqüente fragilização, com o intuito de neutralizá-la em termos de poder. Esse enfraquecimento psíquico pode levar o indivíduo vitimizado a uma paulatina despersonalização. Sem dúvida, trata-se de um processo disciplinador em que se procura anular a vontade daquele que, para o agressor, se apresenta como ameaça.

nismo da organização do trabalho sobre o comportamento dos trabalhadores.

Especialmente no campo da Sociologia do Trabalho, as pesquisas vêm analisando as formas pelas quais os trabalhadores rompem com a severidade da organização do trabalho. Como afirma Buscatto (2002), tanto na França como nos EUA, as pesquisas revelaram "organizações de trabalho clandestinas" e formas de resistência dos trabalhadores em resposta ao controle gerencial.

Nas abordagens teóricas que concebem a organização do trabalho como parte da disputa entre capital e trabalho, discutemse os instrumentos de controle e pressão sobre os trabalhadores, acompanhados da
${ }^{8}$ Segundo o médico psiquiatra e coordenador do Ambulatório de Ansiedade do Hospital das Clínicas de São Paulo, Marcio Bernik, a síndrome do pânico é uma enfermidade que se caracteriza por crises inesperadas de medo e desespero, despertando no paciente a impressão de morte ocasionada por um ataque súbito. Os sintomas mais comuns são aceleração cardíaca, falta de ar e sudorese excessiva. Os pacientes sofrem com a doença especialmente por não saberem quando isso ocorrerá novamente. Disponível em: http: www.drauzio varella.com.br/entrevistas/panico9. asp. Acesso em: 25 jan. 2006. 
${ }^{9} \mathrm{O}$ movimento luddita surgiu na Inglaterra durante a Revolução Industrial. Os operários quebravam as máquinas como resposta ao sistema capitalista e por entenderem que estas não eram neutras, pois geravam maior lucro para o capitalista e cerceavam a autonomia dos trabalhadores.
${ }^{10}$ Jargão da área da informática para indicar a súbita interrupção de uma ligação ou conexão. moral disciplinar e da "expropriação do saber como forma de aumentar seu poder sobre a força de trabalho" (LEITE, 1994, p. 55). Nessa perspectiva, o movimento luddita $^{9}$ configura-se como um protesto contra as práticas disciplinares e contra esse uso específico da tecnologia e não exatamente contra a tecnologia. O avanço da técnica levou à intensificação da criação de padrões de comportamento e atitudes nos primórdios da produção industrial.

Os mesmos modelos praticados naquele período estão presentes hoje no trabalho em telemarketing: o "cartão de ponto", com seu formato tradicional, não existe nas centrais, no entanto, ele é acionado no momento que os operadores inserem seu login e estão aptos a fazer e receber chamadas; a circulação pelo recinto, por sua vez, também é controlada pelo supervisor, conforme já se disse.

No entanto, mesmo sob essas inúmeras condições adversas, os trabalhadores encontram seus meios para fazer frente às normas disciplinares que julgam excessivas, e Simone Weis ilustra de maneira contundente os recursos que criam para se esquivar do controle:

É através dos meios mais grosseiros, usando, como estimulante, ao mesmo tempo, a sujeição e a isca da gratificação - em suma - por um método de domesticação que não se dirige a nada do que é propriamente humano, doma-se o operário como se doma um cão, combinando o chicote com os pedaços de açúcar. Felizmente não alcançam nunca um êxito total, porque nunca a racionalização é perfeita e porque, graças a Deus, o chefe da oficina não conhece nunca tudo. Restam meios de tirar o corpo fora, mesmo para um operário não qualificado. (WEIS, 1979, apud LEITE, 1994, p. 64)

Os trabalhadores sempre foram paulatinamente construindo formas de negar o controle demasiado, e são essas formas de rompimento com a rigidez que surgem no ambiente do teleatendimento, instaurando uma cumplicidade silenciosa entre colegas que nem sempre precisam ser declaradas.

Entre as interdições impostas aos operadores nas centrais de atendimento estão a de falar ao telefone celular e a de fazer ou receber ligações externas particulares, que são bloqueadas pelo sistema. Uma das formas de burlarem essas normas é gerando solidariedade, em princípio negada pela organização do trabalho.
Sobre compartilhar com os colegas os "achados" para contornar as regras do trabalho, os entrevistados relatam estabelecer determinados olhares e gestos que confirmam uma "partilha silenciosa”.

As situações são inusitadas, seja por ser um ambiente predominantemente composto por jovens que buscam a descontração de maneira criativa, seja porque, ao mesmo tempo, revelam a ambigüidade cotidiana vivida por esses trabalhadores, pois, de um lado, a fala é o movimento no trabalho, porém, por outro, não podem comunicar-se entre si.

A alternativa encontrada por essa equipe para transgredir as regras da não comunicação e também suavizar as pressões pela ampliação das vendas foi aprenderem a LIBRAS, língua brasileira de sinais:

\section{Minha supervisora vai fazer preleção para falar alguma coisa [com] que ninguém concorda, sempre cobrando venda todos os dias da vida dela, coitada... No começo, a gente se estressava; agora, ninguém mais [se] estressa e ela acha que todo mundo está prestando atenção. Tem um operador [de] que[m] o irmão dá aula para surdos e mudos e tem um livro de piadas em lin- guagem de sinais, e nós aprendemos, e ele traz esse livro e fica contando piada... Enquanto a supervisora fica cobrando es- tatística, venda... a gente ri e ela se acha a pessoa mais importante do mundo, porque parece que está todo mundo olhando para ela... porque ela fica no meio do corredor, de costas para a janela, e esse meu ami- go fica sentado próximo à janela. É muito criativo. É assim que funciona... (Opera- dor de telemarketing, 27 mai. 2005)}

Posto que as chefias não permitem pausas no trabalho, os operadores "criam" suas próprias "pausas clandestinas”, conforme denominação de Lallement (2003). São suspensões temporárias e propositais do atendimento, geradas pelos operadores, que visam amenizar a carga de trabalho e o ritmo determinado pela tecnologia. São mecanismos que descobrem gradativamente para "derrubar"10 o sistema ou apertar o botão que desliga e religa a máquina sem que a supervisão perceba.

Durand (2004) aponta as altas taxas de morbidade em profissões para as quais as empresas ou as chefias exigem muita rapidez, posto que há um desnível entre a velocidade de execução e a responsabilidade intrínseca ao trabalho. Cita como exemplos as telefonistas e os operadores de segurança, entre outros. E pode-se transpor essa situação aos teleoperadores. A Francetele- 
com, inquieta com a ocorrência de quatro suicídios nas centrais de atendimento, encomendou ao sociólogo do trabalho Philipe Zarifian ${ }^{11}$ pesquisa específica sobre o assunto.

Possivelmente concorrem para esse estado - em que em pouco tempo se encontram os operadores - a repetitividade do trabalho, o ritmo em que deve ser realizado e o controle da supervisão. $\mathrm{Na}$ pesquisa realizada por Durand (2004) em diversas situações de trabalho - entre elas, as de centrais de atendimento - os operadores ouvidos crêem que a repetitividade é sinal de uma "deformação profissional" resultante da sobrecarga de trabalho. Dizem "deformação" porque entendem que o desenvolvimento e o desfecho de uma grande parte das ligações leva os operadores a se desligarem do que ouvem e mesmo da fala que eles próprios reproduzem, sintoma de perda de concentração. No estudo, os operadores que trabalhavam com suporte técnico de informática relataram a dificuldade em conectar os pensamentos entre ligações ininterruptas. Nesse trabalho, não há "dias de pico" para a velocidade - ela é uma constante, todos os dias são exatamente iguais e ao mesmo tempo diferentes, pois os interlocutores são sempre outros.

A despeito da imposição de ritmos intensos, pode-se dizer que o trabalho prescrito não é igual ao executado, uma vez que os trabalhadores mobilizam uma série de qualificações tácitas e técnicas que viabi-

\section{Referências bibliográficas}

ALONZO, P. Les rapports au travail et à l'emploi des caissières de la grande distribution. Des petites stratégies pour une grande vertu. Travail et Emploi. n. 76, p. 37-51, 1998.

BATT, R.; DOELLGAST, V.; KWON, H. The U.S. call center industry 2004: national benchmarking report. Ithaca: Cornell University, 2004.

BUSCATTO, M. Les centres d'appels, usines modernes? Les rationalisations paradoxales de la relation téléphonique. Sociol. trav., v. 44, n. 1, p. 99-117, 2002.

La prescription à l'épreuve de la «personnalité»: L'exemple de la relation téléphonique dans un centre d'appels. In: CONGRÈS DE LA SELF, 37, 2002, Aix-

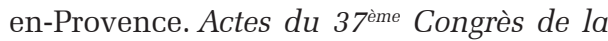

lizam as tarefas de maneiras muitas vezes distantes das estabelecidas pelas normas e procedimentos. Essa atitude do coletivo é indicativa, para os detentores dos meios de produção, de que suas tentativas de controle desses trabalhadores são "sucessos parciais”, como define Harvey (1989), pois os capitalistas não conseguem atingir plenamente os objetivos a que se propõe, como lograr um máximo de produtividade associado à intensificação do trabalho.

Encerramos este artigo com as palavras de um consultor empresarial que reconhece a imagem negativa do setor, quer para os que trabalham no telemarketing, quer para os clientes abordados:

\begin{abstract}
O trabalho nas centrais de atendimento é penoso física e nervosamente (uma boa parte da imagem negativa é originada por essas razões). Será mentiroso de se negar. Passar várias horas do dia ao telefone, com clientes exigentes e diferentes, demanda muita atenção e energia. A pressão resulta em um grande número de problemas, mesmo mínimos. Em tempo real - isto é, imediatamente - exerce uma pressão psicológica importante sobre os operadores. (CAÏAZZO, 2000, p. 126)
\end{abstract}

Assim, Caïazzo mostra que as críticas dirigidas ao setor quanto ao ritmo e à intensificação do trabalho não provêm apenas do campo acadêmico ou jornalístico, mas reitera a impossibilidade de se desprezarem as condições de trabalho vividas por esses jovens, mesmo pela esfera empresarial.
${ }^{11}$ Seminário de pesquisa realizado pelo laboratório Genre et rapports sociaux de sexe/GERS - Iresco, França, em 01 março 2004: Da ética ao trabalho: Sofrimento e resistências com Philippe DAVEZIES, médico, professor-pesquisador em medicina e saúde no trabalho, Université Lyon I, e Philippe ZARIFIAN, sociólogo, professor da Université de Marne la Vallée.
SELF. Aix-en-Provence: GREACT e SELF, 2002a.

CAÏAZZO, B. Les centres d'appels: les nouveaux outils de la relation client. Paris: DUNOD, 2000.

COSSALTER, C. Les plateaux téléphoniques dans les banques et les assurances: continuité et rupture dans la dynamique d'organisation. Réseaux. Paris, v. 20, n. 114, FTR \& D/Hèrmes Sciences Publications, 2002.

COUSIN, O. Les ambivalences du travail, les salariés peu qualifiés dans les centres d'appels. Sociol. trav., v. 44, n. 4, p. 499520, 2002.

DEJOURS, C.; MOLINIER, P. Le travail comme énigme. Sociol. trav., v. 36, HS, p. 35-44, 1994 
DESSUS, N. Les employés des centres d'appels ou la flexibilité sous toutes ses formes. Paris: Ministère de la Jeunesse, de L'éducation National et de la Recherche, 2002.

DURAND, J.-P. La chaîne invisible: travailler aujourd'hui, flux tendu et servitude volontaire. Paris: Le Seuil, 2004.

DURAND, J.-P.; GIRARD, S. Les cahiers d'Évry: attribution, perception et négociation de la charge de travail. Évry: Centre Pierre Naville, 2002.

GALASSO, L. M. R. Humor e estresse no trabalho: fatores psicossociais e benéficos no trabalho dos operadores de telemarketing. 2005. Tese (Doutorado em Saúde Pública) - Faculdade de Saúde Pública, Universidade de São Paulo, São Paulo, 2005.

GOLLAC, M.; VOLKOFF, S. Citius, altius, fortius, l'intensification du travail. Actes de la Recherche en Sciences Sociales, n. 114, p. 54-67, 1996.

Les conditions de travail. Paris: La Découverte, 2000.

GRENIER-PEZÉ, M. Contrainte par corps: lê harcèlement moral. Travail, genre et sociétés, Dossier: harcèlement et violence, les maux du travail, n. 5, p. 29-42, 2001.

GRIP, A.; SIEBEN, I.; JAARSVELD, D. van. Employment and industrial relations in the Dutch call center sector. Maastrich: Research Centre for Education and Labour Market, 2005.

HARVEY, D. A condição pós-moderna. São Paulo: Atlas, 1989.

HELOANI, R. Organização do trabalho e administração: uma visão multidisciplinar. São Paulo: Cortez, 1996.
Gestão e organização no capitalismo globalizado: história da manipulação psicológica no mundo do trabalho. São Paulo: Atlas, 2003.

HIRATA, H.; DOARE, H. Les paradoxes de la mondialisation. Cahiers du Gedisst, n. 21, 1998.

HIRIGOYEN, M.-F. Mal-estar no trabalho: redefinindo o assédio moral. Rio de Janeiro: Bertrand Russel, 2002.

LALLEMENT, M. Temps, travail et modes de vie. Paris: PUF, 2003.

LECHAT, N.; DELAUNAY, J.-C. Les centres d'appels: un secteur en clair-obscur. Paris: L'Harmattan, 2003.

LEITE, M. de P. O futuro do trabalho. São Paulo: Scritta, 1994.

LINHART,. La modernisation des entreprises. Paris: La Découverte, 2004.

MONTMOLLIN, M. Actualité du taylorisme. In: MONTMOLLIN, M.; PASTRE, O. (orgs.). Le taylorisme. Paris: La Découverte, 1984.

TAYLOR, F. Princípios de administração científica. São Paulo: Atlas, 1995.

TERSSAC, G. Autonomie dans le travail. Paris: PUF, 1992.

VENCO, S. Telemarketing nos bancos: o emprego que desemprega. Campinas: Edunicamp, 2003.

- Tempos moderníssimos nas engrenagens do telemarketing. 2006. Tese (Doutorado em Educação) - Faculdade de Educação, Universidade Estadual de Campinas, Campinas, 2006. 